\title{
Determination of Colchicine in Pharmaceutical Formulations and Urine by Multiple-Pulse Amperometric Detection in an FIA System Using Boron-Doped Diamond Electrode
}

\author{
Débora A. R. Moreira, ${ }^{a, b}$ Fernando M. de Oliveira, ${ }^{b, c}$ Dilton M. Pimentel, ${ }^{b}$ \\ Tiago J. Guedes, ${ }^{b}$ Rita C. S. Luz, ${ }^{d}$ Flávio S. Damos, ${ }^{d}$ Arnaldo C. Pereira, ${ }^{a}$ \\ Rodrigo A. B. da Silva ${ }^{e}$ and Wallans T. P. dos Santos $*, f$ \\ ${ }^{a}$ Departamento de Ciências Naturais, Universidade Federal de São João Del-Rei, \\ 36301-160 São João Del-Rei-MG, Brazil \\ ${ }^{b}$ Departamento de Química, Universidade Federal dos Vales do Jequitinhonha e Mucuri (UFVJM), \\ Rodovia MGT 367, km 583, No. 5000, Alto da Jacuba, 39100-000 Diamantina-MG, Brazil \\ 'Instituto Federal de Minas Gerais (IFMG), Rua Itamarati, 140, \\ Bairro São Caetano, 32677-564 Betim-MG, Brazil \\ ${ }^{d}$ Departamento de Química, Universidade Federal do Maranhão, 65080-805 São Luís-MA, Brazil \\ eInstituto de Química, Universidade Federal de Uberlândia, 38400-902 Monte Carmelo-MG, Brazil \\ ${ }^{f}$ Departamento de Farmácia, Universidade Federal dos Vales do Jequitinhonha e Mucuri (UFVJM), \\ Rodovia MGT 367, km 583, No. 5000, Alto da Jacuba, 39100-000 Diamantina-MG, Brazil
}

\begin{abstract}
This work presents a simple and fast method for colchicine $(\mathrm{CO})$ determination in pharmaceutical formulations and urine by multiple pulse amperometry (MPA) with flow injection analysis (FIA) system using a boron-doped diamond electrode. In optimized conditions, it was possible to quantify $\mathrm{CO}$ in urine samples without interference of uric acid and ascorbic acid. The working linear range for $\mathrm{CO}$ quantification was achieved from $1.0 \times 10^{-7}$ to $0.5 \times 10^{-3} \mathrm{~mol} \mathrm{~L}^{-1}$ with a low limit of detection of $2.14 \times 10^{-8} \mathrm{~mol} \mathrm{~L}^{-1}$. Furthermore, the proposed method showed high repeatability for 10 consecutive injections of $1.0 \times 10^{-4} \mathrm{~mol} \mathrm{~L}^{-1} \mathrm{CO}$ (relative standard deviation $=1.28 \%$ ) and good analytical frequency (30 determinations per hour). The addition and recovery studies in all pharmaceutical samples were approximately $100 \%$ and the results for CO determination were compared by high performance liquid chromatography (HPLC) with UV detection.
\end{abstract}

Keywords: colchicine, boron-doped diamond, multiple pulse amperometry, flow-injection analysis

\section{Introduction}

Colchicine (CO) is an anti-inflammatory used in treatment of acute gouty arthritis. This drug has low therapeutic index, so the therapeutic effective concentration range is very narrow. Inadequate dose of $\mathrm{CO}$ presents some side effects, such as severe gastrointestinal distress, hepatocellular insufficiency, central nervous system dysfunction, among other problems. ${ }^{1-5}$ Thereby, CO quantification in pharmaceutical and biological samples is very important to monitor the treatment of patients and

*e-mail: wallanst@ufvjm.edu.br perform pharmacological studies of this drug, beyond performing an efficient quality control of its formulations. ${ }^{5-7}$ The structural formula of $\mathrm{CO}$ is presented in Figure 1.

Identification tests of $\mathrm{CO}$ in pharmaceutical formulations described in pharmacopoeias are based in infrared<smiles>COc1cc2c(c(OC)c1OC)-c1ccc(OC)c(=O)cc1[C@@H](NC(C)=O)CC2</smiles>

Figure 1. Structural formula of CO. 
absorption spectrophotometry, absorption in UV range or change of color in reaction solution containing ferric chloride..$^{8-10}$ The International Pharmacopoeia ${ }^{10}$ suggests UV absorption for calculating tablet contents of CO. Quantification of this drug in urine samples and other matrices in general is performed by high performance liquid chromatography (HPLC) with UV detection. ${ }^{1-13}$ Some methods for CO determination by HPLC coupled with mass spectrometry ${ }^{14,15}$ and spectrophotometry, ${ }^{16}$ as well as immunoassay ${ }^{17}$ were also found in the literature. Despite HPLC technique having advantages as high selectivity and reliability, it is not so suitable for routine analysis in pharmaceutical industries due to high costs and low sample throughput. In this context, the electroanalytical methods have been widely applied to such samples, providing a simple, fast and low-cost analysis. ${ }^{18-20}$ These advantages can justify the number of works that have already been reported for electrochemical behavior studies of $\mathrm{CO}$ and its determination using different working electrodes. ${ }^{3,21-30}$ Among these, the boron-doped diamond (BDD) electrode was used for $\mathrm{CO}$ determination in pharmaceuticals and human serum samples. ${ }^{30}$ The BDD electrode is widespread in electroanalytical methods with some advantages in comparison with other electrodes, such as high stability and low background current. ${ }^{31-37}$

Although electroanalytical methods have presented the above-mentioned advantages for $\mathrm{CO}$ determination, these methods did not present a highly selective determination of $\mathrm{CO}$ in biological samples with presence of large excess of interferants, such as ascorbic acid (AA) and uric acid (UA). Furthermore, the quality control of drugs requires faster and simpler methods for routine analysis.

According to Felix and Angnes, ${ }^{38}$ the flow injection analysis (FIA) system with amperometric detection has been used as an interesting alternative to improve speed and simplicity of drug electroanalysis. Additionally, multiplepulse amperometry (MPA) can provide advantages over classic amperometry (constant potential) such as improved stability (constant cleaning of working electrode surface during the measurements) and selectivity (detection of analyte in a potential without interferants). FIA-MPA detection was used for the first time by dos Santos et al. ${ }^{39}$ for simultaneous determination of AA and paracetamol. This method has been used in other simultaneous determinations, such as for two synthetic colorants in food samples, ${ }^{40}$ two $^{41}$ or three ${ }^{42}$ synthetic antioxidants in food samples, and two or three drugs in pharmaceutical samples. ${ }^{43-45}$ Moreover, MPA detection has been used to improve the selectivity in the quantification of electroactive compounds, ${ }^{46,47}$ and improve precision by the addition of an internal standard in flow analysis ${ }^{48}$ or by the reduction of the contamination of the working electrode..$^{49,50}$ The MPA can also be used for oxidation (or reduction) products detection of an analyte. ${ }^{51}$

Thereby, this paper presents a simple and fast strategy for selective determination of $\mathrm{CO}$ in pharmaceutical formulations and urine samples (recovery studies) using FIA-MPA system and BDD as working electrode.

\section{Experimental}

\section{Reagents and solutions}

CO was obtained from Sigma-Aldrich (São Paulo, Brazil); AA, UA, sulfuric acid and sodium dihydrogen phosphate/sodium hydrogen phosphate from Vetec (Duque de Caxias, Brazil); and acetic acid/sodium acetate and boric acid/borate sodium from Merck (Rio de Janeiro, Brazil). All reagents were of analytical grade and used without any further purification. Stock solutions of CO, AA and UA were freshly prepared with deionized water (Milli-Q system, Millipore, Bedford, MA, USA) with resistivity of $18.2 \mathrm{M} \Omega \mathrm{cm}$ at $298 \mathrm{~K}$. Sulfuric acid solutions (0.1 and $0.3 \mathrm{~mol} \mathrm{~L}^{-1}$ ) and Britton-Robinson buffer with different values of $\mathrm{pH}$ (2.0 to 12.0) were used as supporting electrolytes in electrochemical measurements. The Britton-Robinson buffer was composed of $0.1 \mathrm{~mol} \mathrm{~L}^{-1}$ boric acid, $0.1 \mathrm{~mol} \mathrm{~L}^{-1}$ acetic acid and $0.1 \mathrm{~mol} \mathrm{~L}^{-1}$ phosphoric acid. The buffer $\mathrm{pH}$ values were adjusted using sodium hydroxide and hydrochloric acid.

Human urine samples were collected from healthy volunteers and diluted (100 times) in supporting electrolyte without any sample pre-treatment for the FIA-MPA detection. The pharmaceutical samples of $\mathrm{CO}$ were purchased at local pharmacies in Diamantina-MG (Brazil). The tablets $(n=20)$ of CO were powdered in a mortar, and a weight corresponding to one tablet was dissolved in supporting electrolyte using an ultrasonic bath for $10 \mathrm{~min}$ prior the FIA-MPA detection.

\section{Instrumentation and apparatus}

The BDD film (8000 ppm of doping level) was acquired from Neo Coat SA (La Chaux-de-Fonds, Switzerland). A homemade electrochemical wall-jet cell was used for the electrochemical experiments, with a $\mathrm{Pt}$ wire as auxiliary electrode, and an $\mathrm{Ag} / \mathrm{AgCl}\left(3.0 \mathrm{~mol} \mathrm{~L}^{-1} \mathrm{KCl}\right)$ reference electrode. The area of the BDD working electrode was $0.13 \mathrm{~cm}^{2}$ (delimited by an O-ring with diameter of $0.4 \mathrm{~cm}$ ). Before the measurements, different pretreatments were performed in the working electrode placed in FIA cell containing $0.5 \mathrm{~mol} \mathrm{~L}^{-1} \mathrm{H}_{2} \mathrm{SO}_{4}$ solution. For anodic activation was applied $+1.0 \mathrm{~mA}$ during $120 \mathrm{~s}$ and for cathodic was 
applied $-30.0 \mathrm{~mA}$ during $360 \mathrm{~s}$. Such pretreatment was carried out once a day.

In the FIA analysis, a single-line system was employed using polyethylene tubing of $1.0 \mathrm{~mm}$ (i.d.). The injection system consisted of a manual acrylic injector with polyethylene tubes of $0.5 \mathrm{~mm}$ (i.d.). The flow rate was controlled by a peristaltic pump (Gilson Minipuls 3, Villiers-le-Bel, France). The flow rates were evaluated from 0.5 to $5.0 \mathrm{~mL} \mathrm{~min}^{-1}$, and the injection volumes from 50 to $400 \mu \mathrm{L}$. All electrochemical measurements were carried out at room temperature in absence of oxygen (previously removed with nitrogen gas bubbling).

\section{Results and Discussion}

\section{Electrochemical study of $\mathrm{CO}$}

Cyclic voltammetry (CV) was used to evaluate the electrochemical behavior of $\mathrm{CO}$ on the surface of BDD working electrode in Britton-Robinson buffer solutions at different $\mathrm{pH}$ (2 to 12) and $\mathrm{H}_{2} \mathrm{SO}_{4}$ solution $\left(\mathrm{pH}_{\text {apparent }} 1\right)$. As shown in Figure 2, $0.1 \mathrm{~mol} \mathrm{~L}^{-1} \mathrm{H}_{2} \mathrm{SO}_{4}$ supporting electrolyte presented a better sensitivity to $\mathrm{CO}$ electrochemical processes with four oxidation peaks at about $+0.70,+0.93$, +1.20 and $+1.40 \mathrm{~V}$ and one reduction peak at $-0.60 \mathrm{~V}$. The first two oxidation processes for $\mathrm{CO}$ are more clearly presented in Figure 3. In contrast, Stanković et al. ${ }^{30}$ noticed only two processes on BDD electrode (cathodically pretreated) in $\mathrm{pH} 2$ to 10 and some reduction process.

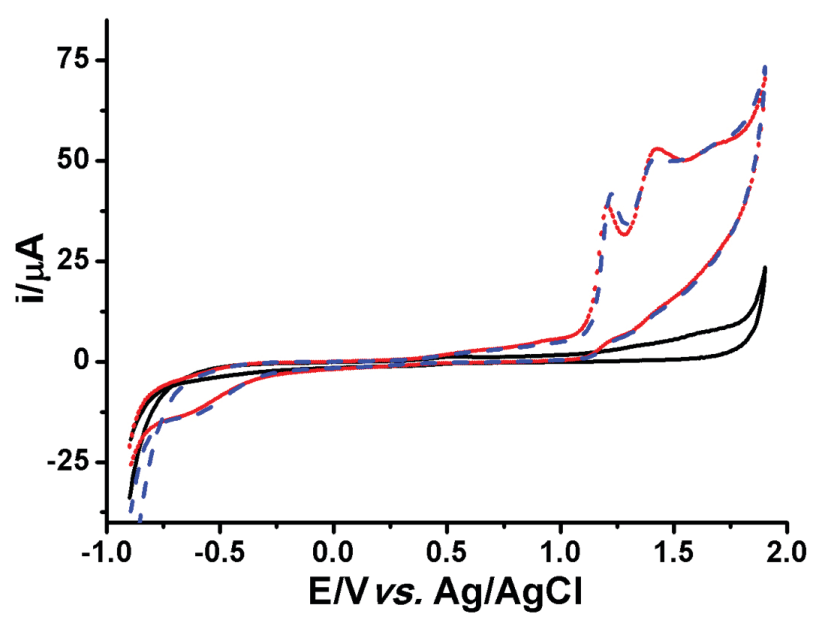

Figure 2. Cyclic voltammograms in $0.1 \mathrm{~mol} \mathrm{~L}^{-1} \mathrm{H}_{2} \mathrm{SO}_{4}$ supporting electrolyte (black line) at BDD electrode and in the presence of $1.0 \mathrm{mmol} \mathrm{L}^{-1} \mathrm{CO}$ after cathodic (blue dashed line) and anodic (red dotted line) treatment. Scan rate: $50 \mathrm{mV} \mathrm{s}^{-1}$.

It can also be verified in Figure 2 that the electrochemical behavior of $\mathrm{CO}$ on BDD after the cathodic or anodic pretreatments presented similar oxidation currents and

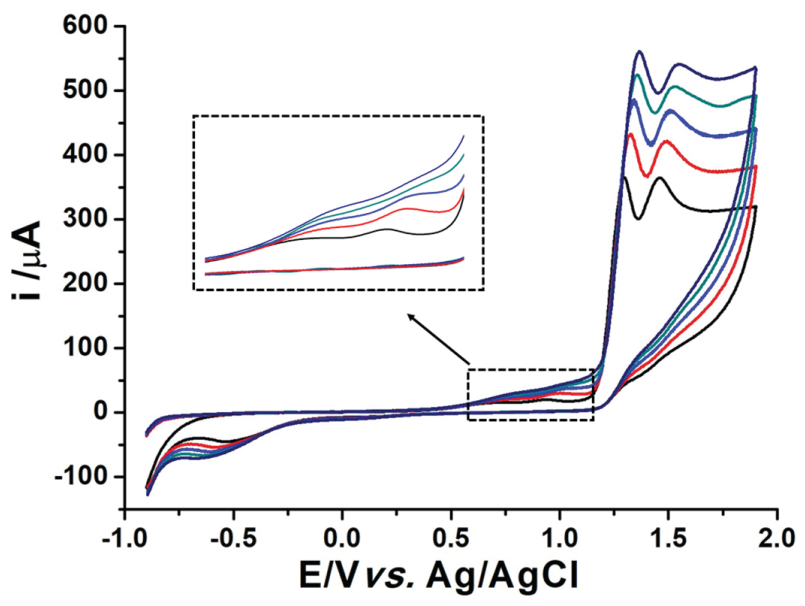

Figure 3. Cyclic voltammograms of $5.0 \mathrm{mmol} \mathrm{L}^{-1} \mathrm{CO}$ at $\mathrm{BDD}$ electrode in $0.1 \mathrm{~mol} \mathrm{~L}^{-1} \mathrm{H}_{2} \mathrm{SO}_{4}$. Scan rate: 50 to $150 \mathrm{mV} \mathrm{s}^{-1}$. Inset: the first two oxidation processes.

potential peaks. However, the cathodic treatment was chosen due to its better cleaning of BDD electrode surface after some measurements of $\mathrm{CO}$ by the proposed method.

The dependence on $\mathrm{CO}$ electrochemical processes was evaluated. When the scan was performed in potential range from -1.0 to $+1.0 \mathrm{~V}$ no reduction processes were noted (not shown), suggesting $\mathrm{CO}$ is not directly reduced in this potential range on BDD electrode. However, when the scan was performed only until oxidation process of $\mathrm{CO}$ at $+1.2 \mathrm{~V}$, the reduction peak $(-0.6 \mathrm{~V}$, as presented in Figure 2$)$ was observed in the reverse scan of this study, which indicates the reduction process is due to the generated product of the third $\mathrm{CO}$ oxidation.

In addition, the effect of the scan rate (v) over currents for all oxidation peaks of $\mathrm{CO}$ was studied by changing the scan from 50 to $150 \mathrm{mV} \mathrm{s}^{-1}$ (Figure 3) and the regression equations revealed a linear behavior between the square root of the scan rate $\left(\mathrm{v}^{1 / 2}\right)$ and the peak current (Ip) for all processes, suggesting the $\mathrm{CO}$ mass transport process is controlled by diffusion on the BDD electrode.

The electrochemical behavior of $\mathrm{CO}$ has already been reported in other carbon-based electrodes by authors such as Zhang, ${ }^{21}$ who performed only a process of irreversible oxidation of $\mathrm{CO}$ by $\mathrm{CV}$ at approximately $+1.12 \mathrm{~V}$ on glassy carbon electrode in $0.1 \mathrm{~mol} \mathrm{~L}^{-1}$ perchloric acid medium, and no reaction mechanism was proposed. Bodoki et al. ${ }^{22}$ showed that it is possible to obtain a quasi-reversible system using a graphite-based electrode in solution of perchloric and phosphoric acids ( $\mathrm{pH} 2.05$ ). These authors observed two well-defined oxidation peaks at 1.06 and $1.22 \mathrm{~V}$ and one peak of reduction at $-1.04 \mathrm{~V}$.

A systematic mechanistic study for the oxidation and reduction processes of $\mathrm{CO}$ was carried out by Bodoki et al ${ }^{3,24}$ For the mechanism study of $\mathrm{CO}$ oxidation, ${ }^{24}$ 
electrochemistry coupled to mass spectrometry with two different types of electrolytic cells (aqueous or non-aqueous medium) and different working electrodes (glassy carbon, gold, platinum and BDD) were used..$^{24}$ The main product observed for $\mathrm{CO}$ oxidation at around $+1.0 \mathrm{~V}\left(v s . \mathrm{Pd} / \mathrm{H}_{2}\right)$ in a large $\mathrm{pH}$ range was the 7-hydroxy derivative of $\mathrm{CO}$. The authors also reported several other generated oxidation products for $\mathrm{CO}$ at $+1.0 \mathrm{~V}\left(v s . \mathrm{Pd} / \mathrm{H}_{2}\right)$, which could explain the two first oxidation peaks noticed in this work (Figure 3). When potentials above $+1.4 \mathrm{~V}\left(v s . \mathrm{Pd} / \mathrm{H}_{2}\right)$ were applied, Bodoki et $a l .{ }^{24}$ reported the second oxidation process of $\mathrm{CO}$ as being due to epoxidation (and/or multiple hydroxylation). For the mechanism study of $\mathrm{CO}$ reduction, Bodoki et $a l .{ }^{3}$ showed the possibility of $\mathrm{CO}$ direct reduction at a diamond working electrode. On the other hand, this work presents a reduction process dependent on oxidation process at $+1.0 \mathrm{~V}$ on BDD electrode ( $v s . \mathrm{Ag} / \mathrm{AgCl}$ ), suggesting a different reduction process than that reported by these authors. Therefore, the reduction process mechanism for the product generated by $\mathrm{CO}$ oxidation (as presented in this work) requires a deeper investigation.

\section{Optimization parameters of FIA-MPA detection}

For MPA detection, two potential pulses were applied in sequence on BDD electrode (chosen with basis on the electrochemical behavior of $\mathrm{CO}$, Figure 2): $+1.7 \mathrm{~V}$ for $500 \mathrm{~ms}$ for $\mathrm{CO}$ oxidation and $-1.1 \mathrm{~V}$ for $30 \mathrm{~ms}$ for reduction of $\mathrm{CO}$ oxidation products (generated in third oxidation process). The pulse times, as well as the injection volume and flow rate (FIA parameters), were optimized considering the best compromise among sensitivity, selectivity and sampling rate. AA and UA are electroactive interferants commonly found in urine sample, but both do not exhibit reduction peaks on BDD electrode. Thus, a study was conducted to find out what concentration of AA and UA would not affect the analytical signal of $\mathrm{CO}$ at $-1.1 \mathrm{~V}$ during the analysis. However, it was observed that AA and UA reacted with $\mathrm{CO}$ oxidized at the electrode surface, lowering the peak reduction signal at $-1.1 \mathrm{~V}$. This behavior has been reported by dos Santos et al. ${ }^{39}$ for determination of dopamine in the presence of AA. The authors evaluated that the chemical reaction between AA and dopamine was inhibited in more acidic media, and an electrolyte of $0.2 \mathrm{~mol} \mathrm{~L}^{-1} \mathrm{H}_{2} \mathrm{SO}_{4}$ was used to minimize interference of AA. Similarly, an evaluation regarding decrease of the $\mathrm{CO}$ reduction peak signal was performed as a function of acid concentration of the electrolyte in the presence of AA and UA. The best results were obtained with $0.3 \mathrm{~mol} \mathrm{~L}^{-1}$ sulfuric acid, as can be seen in Figure 4, where the CO signal is not significantly attenuated (3\%) in the presence of AA and
UA. Figure 4 shows the FIA-MPA responses after duplicate injections of solutions containing only $\mathrm{CO}$, only AA, only $\mathrm{UA}$ and a solution containing a mixture of $\mathrm{CO}, \mathrm{AA}$ and $\mathrm{UA}$ at the same concentration. However, a biological sample, such as urine, has high concentrations of AA and UA, and thus the current signal of $\mathrm{CO}$ was evaluated in the presence of high concentrations of these interferants (Table 1). As can be seen in Table 1, the CO signal remained constant even in the presence of AA or UA in concentration higher than 100 -fold.

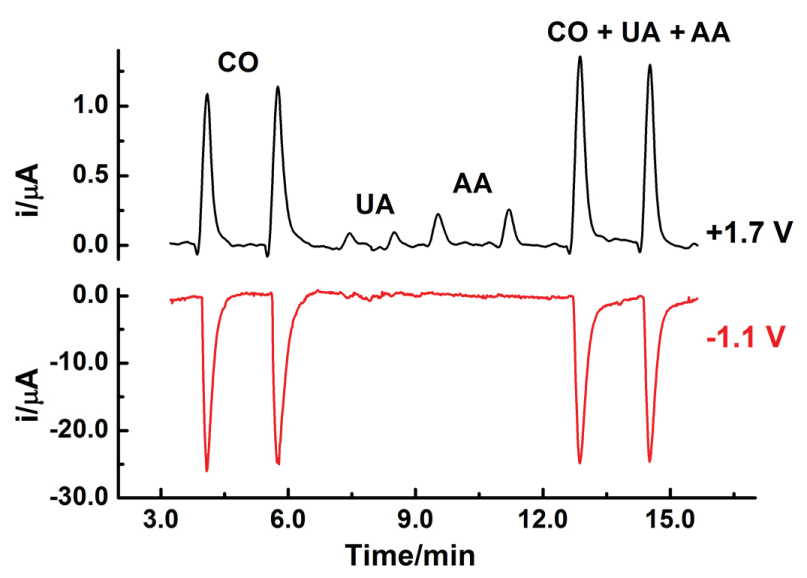

Figure 4. Amperometric responses obtained by FIA-MPA method after duplicate injections of solutions containing only $\mathrm{CO}, \mathrm{AA}, \mathrm{UA}$ and a mixture of $\mathrm{CO}+\mathrm{AA}+\mathrm{AU}\left(10 \mu \mathrm{mol} \mathrm{\textrm {L } ^ { - 1 }}\right.$ for all analytes $)$. Electrolyte: $0.3 \mathrm{~mol} \mathrm{~L}^{-1} \mathrm{H}_{2} \mathrm{SO}_{4}$; flow rate: $3.0 \mathrm{~mL} \mathrm{~min}^{-1}$; injected volume: $330 \mu \mathrm{L}$. Potential pulses applied at $1.7 \mathrm{~V}$ for $500 \mathrm{~ms}$ (black upper line) and $-1.1 \mathrm{~V}$ for $30 \mathrm{~ms}$ (red bottom line) on BDD electrode.

Table 1. Current signal relation for CO detection by FIA-MPA obtained after triplicate injections of solutions containing only $2.0 \mu \mathrm{mol} \mathrm{L}{ }^{-1} \mathrm{CO}$ and with increasing concentrations of AA and UA

\begin{tabular}{lcc}
\hline$[$ Interferant $] /[\mathrm{CO}]$ & $\begin{array}{c}\text { CO current signal for } \\
{[\mathrm{AA}] /[\text { [CO] relation / \% }}\end{array}$ & $\begin{array}{c}\mathrm{CO} \text { current signal for } \\
{[\mathrm{UAO}] \text { relation / \% }}\end{array}$ \\
\hline 1 & 100.5 & 100.1 \\
50 & 101.6 & 98.6 \\
100 & 104.2 & 105.0 \\
\hline
\end{tabular}

CO: colchicine; AA: ascorbic acid; UA: uric acid.

Repeatability studies

A repeatability study of the proposed method was evaluated, in which 10 consecutive injections of $1 \times 10^{-4} \mathrm{~mol} \mathrm{~L}^{-1} \mathrm{CO}$ solution were analyzed in the FIA-MPA under the optimized conditions. As presented in Figure 5, the relative standard deviation $(\mathrm{RSD})$ value $(\mathrm{n}=10)$ found for reduction peaks (acquired at $-1.1 \mathrm{~V}$ ) was only $1.28 \%$, demonstrating an outstanding precision of the proposed method. Using the optimized conditions, the FIA-MPA system provided an analytical frequency of 30 injections per hour, suitable for application in routine analysis. 


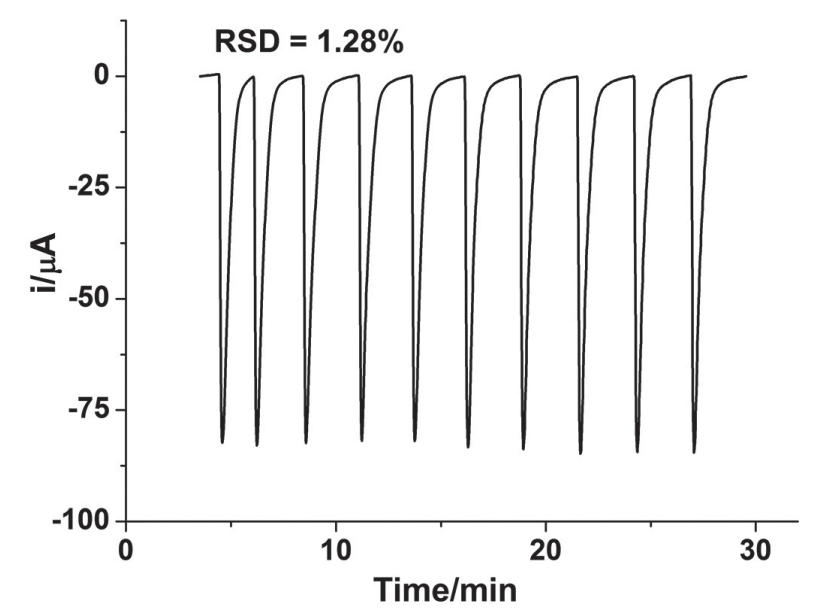

Figure 5. Amperogram obtained at $-1.1 \mathrm{~V}$ for $30 \mathrm{~ms}$ by FIA-MPA of 10 consecutive injections of $10 \mu \mathrm{mol} \mathrm{L}^{-1} \mathrm{CO}$. Electrolyte: $0.3 \mathrm{~mol} \mathrm{~L}^{-1} \mathrm{H}_{2} \mathrm{SO}_{4}$; flow rate: $3.0 \mathrm{~mL} \mathrm{~min}^{-1}$; injected volume: $330 \mu \mathrm{L}$. Potential pulse at $1.7 \mathrm{~V}$ for $500 \mathrm{~ms}$ was applied for oxidation of CO (not shown).

The low RSD value obtained by the proposed method can be justified by association of three factors: (i) BDD, a working electrode with a highly stable surface; (ii) FIA, a highly reproducible hydrodynamic system that allows a continuous cleaning of the working electrode during the analyses; and (iii) MPA detection, that improves the stability of the electrochemical signal due to the permanent application of cleaning pulses.

\section{Analytical parameters}

Analytical parameters of the FIA-MPA method were evaluated for $\mathrm{CO}$ determination in pharmaceutical formulations as well as in human urine. After optimization of all parameters of the proposed method, the calibration curve was constructed by the injection of $\mathrm{CO}$ (triplicate) in the concentration range of $1.0 \times 10^{-7}$ to $0.5 \times 10^{-3} \mathrm{~mol} \mathrm{~L}^{-1}$ (Figure 6). Two linear ranges were observed from this study: 0.1-2.0 and 20-500 $\mu \mathrm{mol} \mathrm{L} \mathrm{L}^{-1}$. The respective linear regressions were: $\mathrm{i}(\mathrm{A})=(8 \pm 5) \times 10^{-7}+(11.3 \pm 0.5) \times[\mathrm{CO}]$ $\left(\mathrm{mol} \mathrm{L}^{-1}\right)$ with $\mathrm{R}=0.997$ and $\mathrm{i}(\mathrm{A})=(6.4 \pm 0.7) \times 10^{-5}+$ $(0.315 \pm 0.003) \times[\mathrm{CO}]\left(\mathrm{mol} \mathrm{L}^{-1}\right)$ with $\mathrm{R}=0.999$. The limits of detection (LOD) and quantification were calculated from the range with smaller concentrations and the values were 0.021 and $0.071 \mu \mathrm{mol} \mathrm{L}^{-1}$, respectively.

The addition-recovery studies in pharmaceutical

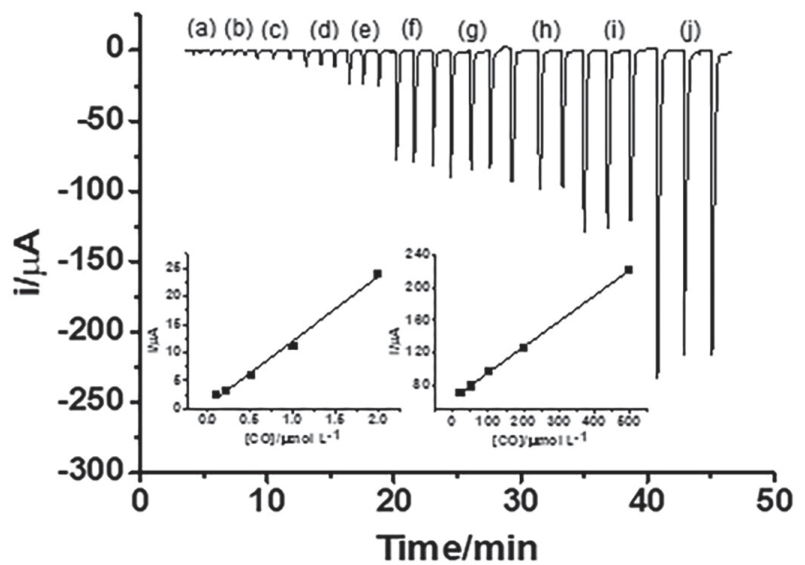

Figure 6. Amperogram obtained by FIA-MPA at $-1.1 \mathrm{~V}$ for $30 \mathrm{~ms}$ after triplicate injections of standard solution containing $\mathrm{CO}$ [(a)-(j): 0.1 to $500 \mu \mathrm{mol} \mathrm{L}{ }^{-1}$. Respective calibration curves are shown in the inset. Electrolyte: $0.1 \mathrm{~mol} \mathrm{~L}^{-1} \mathrm{H}_{2} \mathrm{SO}_{4}$; flow rate: $3.0 \mathrm{~mL} \mathrm{~min}^{-1}$; injected volume: $330 \mu \mathrm{L}$. Potential pulse at $1.7 \mathrm{~V}$ for $500 \mathrm{~ms}$ was applied for oxidation of the $\mathrm{CO}$ (not shown).

samples were performed to verify the accuracy of proposed method. The obtained results for the recovery of $\mathrm{CO}$ in pharmaceutical formulations $(\mathrm{n}=3)$ and human urine $(\mathrm{n}=3)$ were $100.2 \pm 1.0 \%$ and $95.0 \pm 5.0 \%$, respectively. The obtained values were close to $100 \%$, indicating the absence of matrix effect in these samples. The obtained results for the determination of $\mathrm{CO}$ in pharmaceutical samples using the proposed method versus the official method (HPLC-UV) are presented in Table 2. Statistical tests ( $F$ and Student's $t$ ) were carried out comparing the results obtained by both methods with a confidence level of $95 \%$. The calculated values of statistical tests were smaller ( $F=12.96$ and $t=2.17$ ) than the tabulated critical values ( $F=19.00$ and $t=2.78$ ), so the results can be considered similar for both methods.

Table 3 shows some analytical parameters obtained by the proposed method for determination of $\mathrm{CO}$ in comparison with others reported in literature. As shown in Table 3, the proposed method presented a wider linear range with LOD and RSD close to or lower than the modified electrodes used for $\mathrm{CO}$ determination. The lowest LOD and RSD for CO determination were achieved at mercury electrode using adsorptive stripping voltammetry $(\mathrm{ASV}),{ }^{27,28}$ but the use of this working electrode presents environmental drawbacks. Moreover, two linear ranges were also obtained in another work employing the BDD

Table 2. Determination of CO in pharmaceutical formulation by FIA-MPA and official method (HPLC-UV). The studies were performed in triplicate

\begin{tabular}{lcccc}
\hline Sample & Ingredient & Labeled mass / mg & Mass (FIA-MPA)/mg & Mass (HPLC-UV) / mg \\
\hline Capsules & CO & 0.500 & $0.541 \pm 0.001$ & $0.543 \pm 0.004$ \\
\hline
\end{tabular}

FIA-MPA: flow injection analysis coupled to multiple-pulse amperometry; HPLC-UV: high performance liquid chromatography with UV detection; CO: colchicine. 
Table 3. Comparison of the proposed method with electrochemical methods reported for CO determination

\begin{tabular}{|c|c|c|c|c|c|c|}
\hline Technique & Electrode & $\begin{array}{c}\text { Linear range / } \\
\left(\mu \mathrm{mol} \mathrm{L} \mathrm{L}^{-1}\right)\end{array}$ & $\begin{array}{c}\text { LOD / } \\
\left.(\mu \mathrm{mol} \mathrm{L})^{-1}\right)\end{array}$ & $\begin{array}{c}\mathrm{RSD}(\mathrm{n}) / \\
\%\end{array}$ & Sample & Reference \\
\hline LSV & PRDE and GRDE & $2000-10000$ & - & - & - & 29 \\
\hline DPV & GCE/PoPD/SWNTs & $0.1-40$ & 0.04 & $5.3(10)$ & biological & 23 \\
\hline DPV & GCEs/AB-DHP & $0.1-10$ & 0.035 & $5.3(5)$ & pharmaceutical & 21 \\
\hline DPV & SPEs & $0.21-3.0$ & 0.103 & - & pharmaceutical & 22 \\
\hline ASV & HDME & $0.05-0.4$ & 0.000026 & $1.8(3)$ & pharmaceutical and biological & 27 \\
\hline DPV & MWCNTs/CPE & $0.01-25$ & 0.008 & $6.85(10)$ & pharmaceutical & 26 \\
\hline ASV & SMDE & $0.01-0.1$ & 0.00013 & $1.1(12)$ & biological & 28 \\
\hline SWASV & GO/Nafion/GCE & $0.05-20$ & 0.015 & $2.8(10)$ & pharmaceutical & 25 \\
\hline DPV & BDD & $1.0-10$ and $10-100$ & 0.26 & $1.7(10)$ & pharmaceutical and biological & 30 \\
\hline FIA-MPA & BDD & $0.1-2$ and $20-500$ & 0.021 & $1.28(10)$ & pharmaceutical and biological & this work \\
\hline
\end{tabular}

LOD: limit of detection; RSD: relative standard deviation; n: number of replicates; LSV: linear sweep voltammetry; PRDE: platinum rotating disc electrode; GRDE: gold rotating disc electrode; DPV: differential pulse voltammetry; GCE/PoPD/SWNTs: poly-o-phenylenediamine-single-wall carbon nanotubes composite modified glassy carbon electrode; GCEs/AB-DHP: acetylene black-dihexadecyl hydrogen phosphate composite film coated glassy carbon electrode; SPEs: graphite-based screen printed electrodes; ASV: adsorptive stripping voltammetry; HDME: hanging drop mercury electrode; MWCNTs/CPE: multiwall carbon nanotubes doped carbon paste electrode; SMDE: static mercury drop electrode; SWASV: square wave adsorptive stripping voltammetry; GO/Nafion/GCE: graphene oxide-Nafion composite film modified glassy carbon electrode; BDD: boron-doped electrode; FIA-MPA: flow injection analysis coupled to multiple-pulse amperometry.

electrode ${ }^{30}$ but the proposed method (FIA-MPA) presented lower LOD and RSD than the ones reported. This can be justified by the higher sensitivity obtained in the FIA system, since the flow decreases the Nernst diffusion layer in working electrode surface. Moreover, in an FIA system the solution (electrolyte) continuously passes over the working electrode surface, allowing a better cleansing of this electrode and improving its stability.

\section{Conclusions}

The proposed FIA-MPA method using the bare BDD working electrode showed some advantages compared to other reported methods for $\mathrm{CO}$ quantification in pharmaceutical formulation and urine samples (recovery studies), such as simple, fast and accurate analysis and low waste generation. Furthermore, the pulsed amperometric detection provided a selective determination of $\mathrm{CO}$ in urine sample even in the presence of high concentrations of AA and UA, without sample treatment.

\section{Acknowledgments}

The authors are grateful to the Brazilian agencies Fundação de Amparo à Pesquisa do Estado de Minas Gerais (FAPEMIG, APQ-03637-16) and Conselho Nacional de Desenvolvimento Científico e Tecnológico (CNPq, 309208/2015-7 and 475276/2013-2) for financial support.

\section{References}

1. Leung, Y. Y.; Hui, L. L. Y.; Kraus, V. B.; Semin. Arthritis Rheum. 2015, 45, 341.

2. Gilman, A. G.; Hardman, J. G.; Limbird, L. E.; Goodman \& Gilman: as Bases Farmacológicas da Terapêutica, 10a ed.; McGraw-Hill: Rio de Janeiro, 2003.

3. Bodoki, E.; Vlase, L.; Sãndulescu, R.; Electrochem. Commun. 2015, 56, 51 .

4. Deftereos, S.; Ginnopoulos, G.; Papoutsidakis, N.; Panagopoulou, V.; Kossyvakis, C.; Raisakis, K.; Cleman, M. W.; Stefanadis, C.; J. Am. Coll. Cardiol. 2013, 62, 1817.

5. Wallace, S. L.; Semin. Arthritis Rheum. 1974, 3, 369.

6. Slobodnick, A.; Shah, B.; Pillinger, M. H.; Krasnokutsky, S.; Am. J. Med. 2015, 128, 461.

7. Petterman, C.; Bem-Chetrit, E.; Caraco, Y.; Levy, M.; Semin. Arthritis Rheum. 1991, 21, 143.

8. European Pharmacopoeia Commission; European Pharmacopoeia, $5^{\text {th }}$ ed.; Council of Europe: Strasbourg, 2005.

9. British Pharmacopoeia Commission; British Pharmacopoeia; Stationery Office: London, 2008.

10. World Health Organization; The International Pharmacopoeia: Tests and General Requirements for Dosage Forms; Quality Specifications for Pharmaceutical Substances and Tablets, vol. 5, 3 $3^{\text {rd }}$ ed.; World Health Organization: Geneva, 2003.

11. Fernandez, P.; Bermejo, A. M.; Tabernero, M. J.; LopezRivadulla, M.; Cruz, A.; Forensic Sci. Int. 1993, 59, 15.

12. Ko, R. J.; Li, W. Y.; Koda, R. T.; J. Chromatogr. 1990, 525, 411. 
13. Bartusik, D.; Tomanek, B.; Lattová, E.; Perreault, H.; Tuszynski, J.; Fallone, G.; Bioorg. Chem. 2009, 37, 193.

14. Tracqui, A.; Kintz, P.; Ludes, B.; Rouge, C.; Douibi, H.; Mangin, P.; J. Chromatogr. B: Biomed. Sci. Appl. 1996, 675, 235.

15. Hamscher, G.; Priess, B.; Nau, H.; Panariti, E.; Anal. Chem. 2005, 77, 2421.

16. Singh, D. K.; Srivastava, B.; Sahu, A.; J. Indian Chem. Soc. 2004, 81, 171.

17. Poulev, A.; Deus-Neumann, B.; Bombardelli, E.; Zenk, M. H.; Planta Med. 1994, 60, 77.

18. Uslu, B.; Ozkan, S. A.; Anal. Lett. 2011, 44, 2644.

19. Ozkan, S. A.; Uslu, B.; J. Pharm. Biomed. Anal. 2016, 130, 126.

20. Couto, R. A. S.; Lima, J.; Quinaz, M. B.; Talanta 2016, 146, 801.

21. Zhang, H.; Bioelectrochemistry 2006, 68, 197.

22. Bodoki, E.; Laschi, S.; Palchetti, I.; Sândulescu, R.; Mascini, M.; Talanta 2008, 76, 288.

23. Zhang, X. H.; Wang, S. M.; Jia, L.; Xu, Z. X.; Zeng, Y.; Sens. Actuators, B 2008, 134, 477.

24. Bodoki, E.; Chira, R.; Zaharia, V.; Sandulescu, R.; Electrochim. Acta 2015, 178, 624.

25. Wang, F.; Zhou, J.; Liu, Y.; Wu, S. J.; Song, G.; Ye, B.; Analyst 2011, 136, 3943.

26. Zhang, K.; Zhou, J.; Liu, J.; Li, K.; Li, Y.; Yang, L.; Ye, B.; Anal. Methods 2013, 5, 1830.

27. Kasim, E. A.; Anal. Lett. 2002, 35, 1987.

28. Wang, J.; Ozsoz, M.; Talanta 1990, 37, 783.

29. Bishop, E.; Hussein, W.; Analyst 1984, 109, 623.

30. Stanković, D. M.; Švorc, L.; Mariano, J. F. M. L.; Ortner, A.; Kalcher, K.; Electroanalysis 2017, 29, 2276.

31. Luong, J. H. T.; Male, K. B.; Glennon, J. D.; Analyst 2009, 134, 1965.

32. Peckova, K.; Musilova, J.; Barek, J.; Crit. Rev. Anal. Chem. 2009, 39, 148

33. Zhou, Y.; Zhi, J.; Talanta 2009, 79, 1189.

34. Chailapakul, O.; Siangproh, W.; Tryk, D. A.; Sens. Lett. 2006, $4,99$.
35. Pleskov, Y. V.; J. Anal. Chem. 2000, 55, 1045.

36. Einaga, Y.; Foord, J. S.; Swain, G. M.; Mater. Res. Bull. 2014, 39, 525.

37. Macpherson, J. V.; Phys. Chem. Chem. Phys. 2015, 17, 2935.

38. Felix, F. S.; Angnes, L.; J. Pharm. Sci. 2010, 99, 4784.

39. dos Santos, W. T. P.; Almeida, E. G. N.; Ferreira, H. E. A.; Gimenes, D. T.; Electroanalysis 2008, 20, 1878.

40. Medeiros, R. A.; Lourenção, B. C.; Rocha-Filho, R. C.; Fatibello-Filho, O.; Talanta 2012, 99, 883.

41. Medeiros, R. A.; Lourenção, B. C.; Rocha-Filho, R. C.; Fatibello-Filho, O.; Anal. Chem. 2010, 82, 8658.

42. Bavol, D.; Economou, A.; Zima, J.; Barek, J.; Dejmkova, H.; Talanta 2018, 178, 231.

43. Chaves, S. C.; Aguiar, P. N. C.; Torres, L. M. F. C.; Gil, E. S.; Luz, R. C. S.; Damos, F. S.; Munoz, R. A. A.; Richter, E. M.; dos Santos, W. T. P.; Electroanalysis 2015, 27, 2785.

44. Freitas, J. M.; Oliveira, T. C.; Gimenes, D. T.; Munoz, R. A. A.; Richter, E. M.; Talanta 2016, 146, 670.

45. Gimenes, D. T.; Cunha, R. R.; Ribeiro, M. M. A. C.; Pereira, P. F.; Munoz, R. A. A.; Richter, E. M.; Talanta 2013, 116, 1026.

46. Alecrim, M. F.; Oliveira, F. M.; Guedes, T. J.; Neves, C. D. C.; Mendonça, V. A.; Gil, E. S.; Verly, R. M.; dos Santos, W. T. P.; Electrochim. Acta 2016, 222, 331.

47. Gimenes, D. T.; dos Santos, W. T. P.; Tormin, T. F.; Munoz, R. A. A.; Richter, E. M.; Electroanalysis 2010, 22, 74.

48. Gimenes, D. T.; dos Santos, W. T. P.; Munoz, R. A. A.; Richter, E. M.; Electrochem. Commun. 2010, 12, 216.

49. Lopes Jr., A. C. V.; Luz, R. C. S.; Damos, F. S.; Santos, A. S.; Franco, D. L.; dos Santos, W. T. P.; J. Braz. Chem. Soc. 2012, 23,1800 .

50. Guedes, T. J.; Andrade, G. A. R.; Lima, A. B.; da Silva, R. A. B.; dos Santos, W. T. P.; Electroanalysis 2017, 29, 1.

51. Guedes, T. J.; Alecrim, M. F.; Oliveira, F. M.; Lima, A. B.; Barbosa, S. L.; dos Santos, W. T. P.; J. Solid State Electrochem. 2016, 20, 2445.

Submitted: January 10, 2018 Published online: March 20, 2018 